\section{Military Technical College Kobry El-Kobbah, Cairo, Egypt}

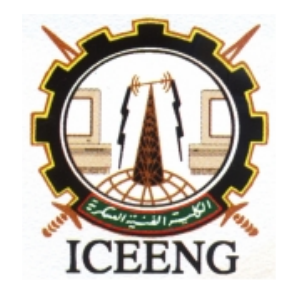

\title{
The Subsurface Nano Indentation Effects on Stainless Steel
}

\author{
By \\ A. Hebatalrahman \\ Dr. Eng. Consultant in Materials Sciences and Materials Applications \\ Egypt
}

\begin{abstract}
$\underline{\text { Abstract: }}$
Stainless steel 316L has a lot of applications in buildings and architectures such as envelopes and clad fixations. Some alloying elements were added to improve pitting corrosion of stainless steel 316L In order to study of the effect of UV laser irradiation on Stainless steel 316L, it was irradiated by $308 \mathrm{~nm}$ Excimer laser at different number of pulses in the range from 2000 pulses to 50000 pulses. The nanoindentation measurements were performed on the surface of both untreated AISI $316 \mathrm{~L}$ stainless steel and on laser irradiated samples in order to determine their hardness, stiffness and elastic properties, the effect of alloying elements on the irradiation process of Austenitic stainless steel was evaluated. The research emphasis that laser irradiation is a promising technique for surface hardening of materials can not be heat treated by conventional methods.
\end{abstract}

